
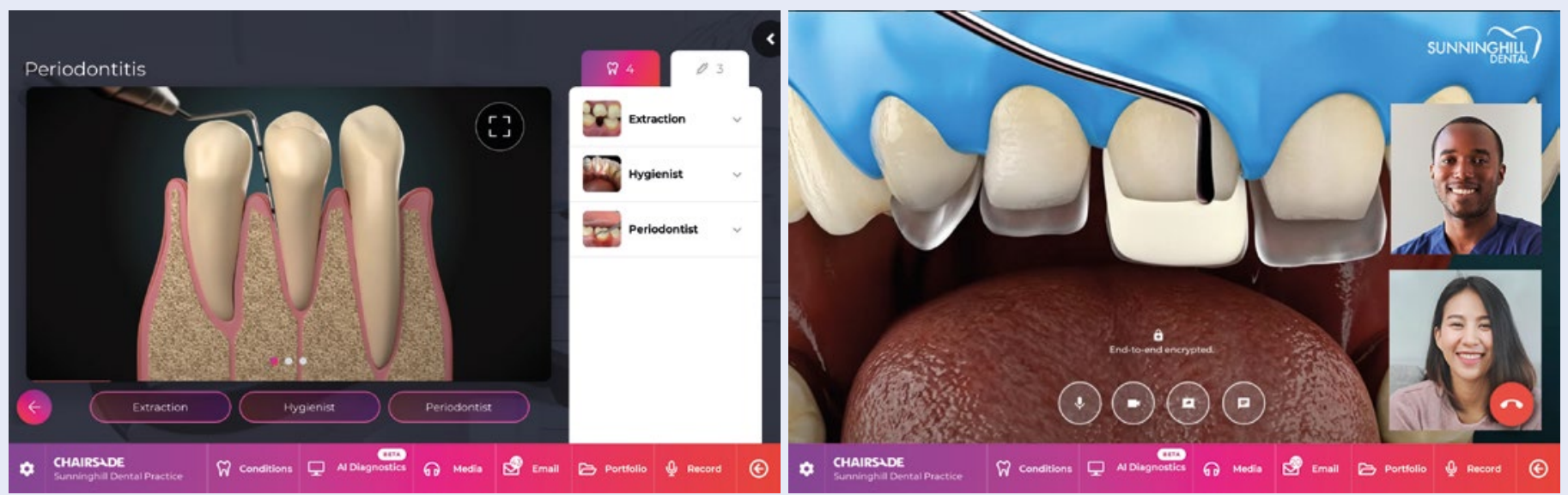

\title{
The chairside experience
} \section{in a COVID-19 world}

\section{David Westgarth}

Editor, BDJ in Practice

$\mathrm{I}$ love the phrase 'routine dentistry'. It has all manner of meanings once you sit down to think about it. What does it really mean? Is it the pitter patter of patient feet from reception to waiting room to dental chair and back again on repeat umpteen times a day? Is it the routine dental practitioners have? Up. Breakfast. Practice. Prepare for first patient. See first patient. Clean down. Prepare for second patient (and so on).

Whatever your definition of routine dentistry, COVID-19 means there is really no such thing at present. Practitioners across the country have had to find ways to adapt their skills and services throughout the pandemic, adaptations that include the chairside experience for patients. After all, how is that even possible when many practices aren't even seeing patients? I spoke to Loven Ganeswaran, founder of Chairsyde Video Consulting, about the future of the patient chairside journey during and post-pandemic.
How have practitioners adapted to not seeing their patients and being able to offer dental education pre and post-appointment?

LG There have obviously been some challenges - we're living in unprecedented times but from my experience weve adapted to technology and the situation remarkably well. We have seen corporates look to technology to minimise long-term disruption for their associates who do not have access to chairside conversations they usually would. We've seen independent practices adapt, mainly through their dentists who offer cosmetic treatments such as Invisalign - and we've seen practice owners offer virtual consultations to manage their workflows. Chairsyde Video Consulting is one such virtual consultation platform, the development of which we accelerated during the pandemic.

Ordinarily you would pigeon-hole young, tech-savvy practitioners as those who have made an easy transition, but that hasn't been the case. With fallow time at 60 minutes in most cases, everyone has looked to maximise their time with patients and in doing so offer them the flexibility to schedule appointments when the clinic is empty.

Has this demand purely been driven by the pandemic or was there an appetite for digital consultations preCOVID-19?

LG The situation we're in clearly has had a lot to do with the increased demand and the rapid pace of its adoption, but that's not to say there wasn't a demand prior to March. Telehealth has been under development since the 1990s, and many studies have already taken place that consider how it can benefit particularly vulnerable communities.

What I would say is the pessimism and doubts about digital and virtual consultations has evaporated very quickly. Yes, the situation demanded that be the case, but conversations I've had with practitioners suggest postCOVID-19 this is a service that will stay and become part of the new norm. The pandemic has busted a lot of myths about dentistry very quickly, one of them being that every consultation should result in a diagnosis. That's not the purpose of Chairsyde Video Consulting. We want to be a face of reassurance. We have a consultation, discuss the patient's history, their options and the costs involved as well as the risks and benefits of any treatment.

So far we've found that patients seem to prefer the digital consultation rather than the in-practice visit, where appropriate. It's more relaxed for one, which is very useful 
considering the relatively high proportion of the population that say they're anxious about a visit to the dentist.

\section{Does that mean you foresee long- term usage post-pandemic rather} than addressing a short-term need? LG I think that's reasonable, yes. With Chairsyde Video Consulting, patients are able to have in-depth consultations before they come into the practice, visualising their options through animations, photography and illustrations. They know what expect and are fully informed ahead of their appointment. If you add the opportunity to connect and reassure patients post-treatment, it's a powerful combination. It is still the dentist's responsibility to assess what is best for the patient - it always has been, always is and always should be. In many cases we can get the patient in on the same day as their consultation for treatment. It's a model that has the potential to help dentistry recover in the long term and get back on its feet. Fallow time severely limits the number of patients you can see on a daily basis. If you can increase your efficiency and see three or four patients during that time virtually, that can only be a positive step.

\section{That's all well and good, but how can you replicate the chairside experience digitally?}

LG If you're having a consultation in your own house and you're talking to a patient from your own office, the mindset is different - there's a level of comfort that doesn't exist in the chair. It appears to help with patient recall too we've found $74 \%$ of patients could recall the dental education and information they were given immediately after their consultation, which is a significant amount. Any increase in compliance is a good thing and an ambition every practitioner should be working towards. At Chairsyde we're monitoring the long-term compliance statistics. Early indications show there's a notable increase in compliance - up almost 32\%.

\section{Could there be a use for accessing previously hard-to-reach patients?} LG Absolutely, yes. Digital consultations will benefit any patient, particularly those struggling to get an NHS dentist, have a phobia or anxiety about a visit. One of our customers uses Chairsyde Video Consulting to reach care homes, which is crucial at the moment. We're also looking into implementing the technology in schools. The pandemic has brought outreach programmes to a halt, and many children that relied on those services have had six months of no interaction. If we can get this technology in front of six-year-olds to talk to them about oral health and show them our preventionfocused animations, that's a scheme that can continue once we're out of the pandemic.

For me, that's the power of communication - good communication can relieve that anxiety and empower patients to make decisions with the aid of a dentist's direction. Imagine if you are speaking to an anxious patient and you're able to put them at ease, give them the information to make the best decision for them - which may include coming into the practice for treatment - and giving them educational presentations to manage their oral health at home. On top of that you have reviews, video catch-ups and regular dialogue, all of which takes place out of the practice. It helps the patient and frees up time in the surgery for you to see patients that are in critical need of your services, which many experts believe will be critical as we come out of the pandemic.

The complete virtual patient journey from booking an appointment and uploading photos to visualising treatment options and delivering post consultation summaries is what will make Chairsyde Video Consulting a potential blueprint for dentistry moving forwards. Personalised dentistry is nothing new, but for me taking a patient-centric approach is the key element to making it work

\section{Do these principles apply to other public oral health needs?}

LG I think so, yes. Dentistry has had to adapt to technology very quickly throughout the pandemic, and we're only just at the tip of the iceberg when it comes to the power of digital. We have more than 300 animations to show patients. Getting the right resources to the right people at the right time isn't easy, but digital can help to overcome those barriers.

For example, the idea of for Chairsyde was born out of a backpacking trip to Sri Lanka where we visited a fairly remote village to deliver some basic dentistry as part of our charity work. We've been able to keep connected since, which is wonderful. There are so many visual learners out there - and I class myself as one of those - so it was about bringing these pillars and strands together. We're currently connected to a Syrian refugee camp, so there are endless possibilities with digital oral health education when used in the right way.
Are there any risks of not being faceto-face with the patient?

LG If adopted in the right way, the risks are as low as they could possibly be. Good communication with a focus on the patient helps to build trust and a rapport. In fact, video consulting sits well alongside the traditional patient journey, enhancing communication, empowering education, providing access whilst freeing up chair time. Our ethos is to integrate into your current workflow rather than be a standalone technology aid. Risk management is something you think about with every patient when they're in the practice, so why should that be any different when the consultation is done digitally?

At every stage of the consultation we time stamp what was said. The technology enables us to track these in the patient's notes so you will always know when they have received the material, that they know why they have received it and that they understand and accept what they are reading. Oral health maintenance is a lifetime thing and one visit doesn't always address the issue the patient is presenting with. Virtual sessions with the use of our technology mitigates the risk of litigation as much as possible - we all know how important that is in the world we live in today.

For further information about Chairsyde Video Consulting and to sign up for a free trial visit www.chairsyde.com

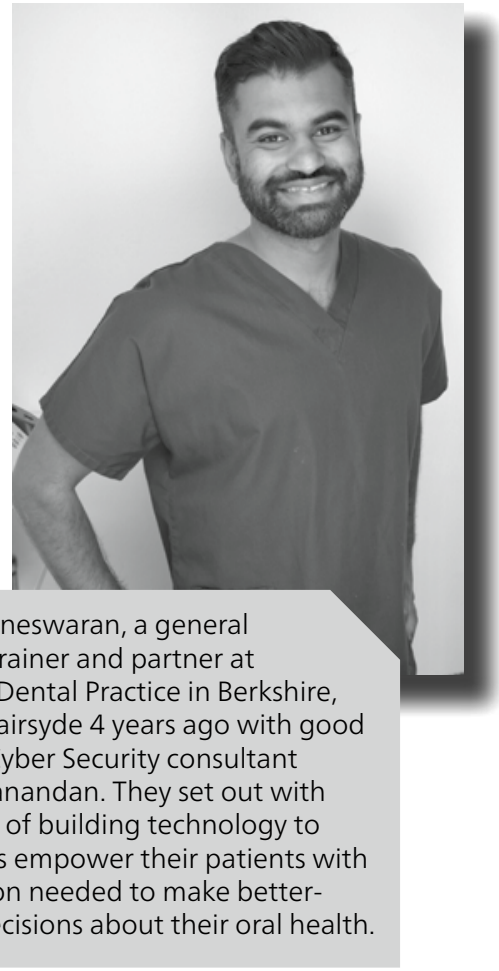

https://doi.org/10.1038/s41404-020-0535-0
Dr Loven Ganeswaran, a general dentist, FD trainer and partner at Sunninghill Dental Practice in Berkshire founded Chairsyde 4 years ago with good friend and Cyber Security consultant the purpose of building technology to help dentists empower their patients with the education needed to make betterinformed decisions about their oral health. Kirishan Sivanandan. They set out with 